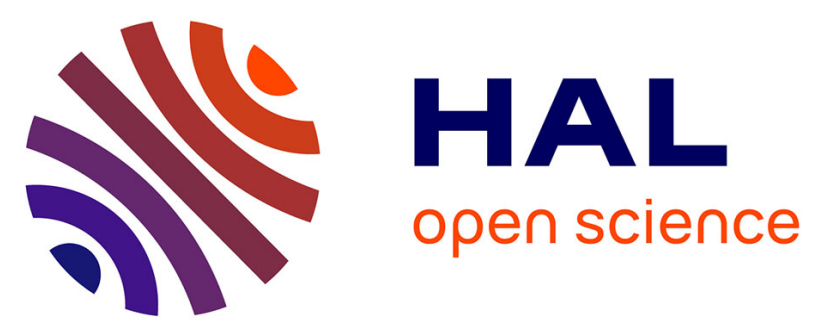

\title{
Founder mutations account for the majority of -attributable hereditary breast/ovarian cancer cases in a population from Tuscany, Central Italy
}

Laura Papi, Anna Laura Putignano, Caterina Congregati, Ines Zanna, Francesco Sera, Doralba Morrone, Mario Falchetti, Marco Rosselli Del Turco, Laura Ottini, Domenico Palli, et al.

\section{To cite this version:}

Laura Papi, Anna Laura Putignano, Caterina Congregati, Ines Zanna, Francesco Sera, et al.. Founder mutations account for the majority of -attributable hereditary breast/ovarian cancer cases in a population from Tuscany, Central Italy. Breast Cancer Research and Treatment, 2008, 117 (3), pp.497-504. 10.1007/s10549-008-0190-3 . hal-00478267

\section{HAL Id: hal-00478267 https://hal.science/hal-00478267}

Submitted on 30 Apr 2010

HAL is a multi-disciplinary open access archive for the deposit and dissemination of scientific research documents, whether they are published or not. The documents may come from teaching and research institutions in France or abroad, or from public or private research centers.
L'archive ouverte pluridisciplinaire HAL, est destinée au dépôt et à la diffusion de documents scientifiques de niveau recherche, publiés ou non, émanant des établissements d'enseignement et de recherche français ou étrangers, des laboratoires publics ou privés. 


\title{
Founder mutations account for the majority of $B R C A 1$-attributable hereditary breast/ovarian cancer cases in a population from Tuscany, Central Italy
}

\author{
Laura Papi · Anna Laura Putignano · Caterina Congregati · Ines Zanna · \\ Francesco Sera - Doralba Morrone - Mario Falchetti - Marco Rosselli Del Turco • \\ Laura Ottini $\cdot$ Domenico Palli $\cdot$ Maurizio Genuardi
}

Received: 13 August 2008/Accepted: 5 September 2008/Published online: 27 September 2008

(C) Springer Science+Business Media, LLC. 2008

\begin{abstract}
Background Germline mutations in the BRCA1 and $B R C A 2$ tumour-suppressor genes predispose to earlyonset breast and ovarian cancer. Although both genes display a highly heterogeneous mutation spectrum, a number of alterations recur in some populations. Only a limited number of founder mutations have been identified in the Italian population so far. Objective To investigate the spectrum of $B R C A 1 / B R C A 2$ mutations in a set of families originary from the Central-Eastern part of Tuscany and to ascertain the presence of founder effects. We also wanted to approximate the age of the most frequent BRCAl founder mutation. Results Overall, four distinct BRCA1 mutations accounted for a large fraction (72.7\%) of BRCAl-attributable hereditary breast/ovarian cancer in families originary from this area. We identified common
\end{abstract}

L. Papi $(\bowtie) \cdot$ A. L. Putignano · C. Congregati · M. Genuardi Medical Genetics Unit, Department of Clinical Physiopathology, University of Florence, Viale Pieraccini, 6, 50139 Florence, Italy e-mail: 1.papi@dfc.unifi.it

I. Zanna $\cdot$ F. Sera $\cdot$ D. Palli

Molecular and Nutritional Epidemiology Unit,

ISPO-Scientific Institute of Tuscany, Florence, Italy

D. Morrone

Senology Unit, ISPO-Scientific Institute of Tuscany,

Florence, Italy

M. Falchetti · L. Ottini

Dipartimento di Medicina Sperimentale,

Università "La Sapienza", Rome, Italy

M. R. D. Turco

Prevenzione e Salute, PRE.SA, Florence, Italy

M. Genuardi

Fiorgen Foundation for Pharmacogenomics, Sesto Fiorentino, Florence, Italy haplotypes for two newly recognised recurrent BRCA1 mutations, c.3228_3229delAG and c.3285delA. The c.3228_3229delAG mutation was estimated to have originated about 129 generations ago. Interestingly, male breast cancer cases were present in 3 out of 11 families with the c.3228_3229delAG mutation. Conclusions The observation that a high proportion of families with $B R C A 1$ alterations from Central-Eastern Tuscany harbours a limited number of founder mutations can have significant impact on clinical management of at risk subjects from this area. In addition, the identification of a large set of families carrying an identical mutation that predisposes to breast and ovarian cancer provides unique opportunities to study the effect of other genetic and environmental factors on penetrance and disease phenotype.

Keywords Hereditary breast/ovarian cancer .

Male breast cancer - BRCA1 - BRCA2 .

Founder mutation

\section{Introduction}

Germline mutations in the BRCA1 (MIM +113705) and $B R C A 2$ (MIM +600185) tumour-suppressor genes predispose to early-onset breast and ovarian cancer. Although many different pathogenic mutations have been identified throughout the whole coding sequence of both genes, a number of alterations recur in some ethnic groups. Well known examples of BRCA1 and BRCA2 founder mutations have been observed in Ashkenazi Jews, Icelanders, Norwegians, Swedes, Finns, French Canadians and Dutch (reviewed in [1]).

Compared to the above mentioned populations, the spectrum of molecular defects associated with genetic 
diseases in countries with a long-standing history of ethnic admixture and migration, like Italy, is usually highly heterogeneous. Nonetheless, a few founder recurrent mutations in BRCAI [2-4] and BRCA2 [5, 6] originated from different regions of Italy have been observed.

In our analysis of breast/ovarian cancer families from the Central-Eastern part of Tuscany, we found four recurrent BRCA1 mutations, one of which was associated with a history of male breast cancer. Haplotype analysis of nine polymorphic markers flanking the BRCAl gene was performed for the two most frequent mutations identified. We found that both sequence variants were derived from common ancestors, and then estimated the number of generations elapsed since the origin of the most frequent mutation, c.3228_3229delAG. Overall, we demonstrate that the vast majority $(72.7 \%)$ of BRCAl-attributable hereditary breast/ovarian cancer families that are originary from this part of Italy harbour a limited number of "regional" mutations.

\section{Materials and methods}

\section{Subjects}

Families were ascertained at the Medical Genetics Unit of the University of Florence and at the ISPO, Scientific Institute for Cancer Prevention of Tuscany, in the period 1999-2005. Pedigrees were reconstructed for at least three generations and demographic data were obtained to determine the geographic origin of both the paternal and the maternal family branches. Where possible, cancers were verified from cancer registries, hospital notes or death certificates. Probabilities of carrying a mutation in the $B R C A 1$ or BRCA2 genes were estimated using the CaGene Software, derived from the BRCAPro model (URL: http://astor.som.jhmi.edu/BayesMendel/brcapro.html) [7]. Genetic testing was offered to affected probands with a calculated $B R C A$ mutation probability $>5 \%$. A total of 104 unrelated probands from Florence and the surrounding provinces of Prato, Pistoia and Arezzo in Central/Eastern Tuscany, underwent BRCA1/2 genetic testing. Two additional male breast cancer families from Tuscany, ascertained in a population-based study [8], were also included for haplotype analysis.

Blood samples from 18 nuclear cancer-free families, originary from Central-Eastern Tuscany, and from 15 noncarrier relatives belonging to Tuscan families segregating $B R C A 1$ recurrent mutations were used to estimate allele frequencies and control haplotypes. Informed consent was obtained from all study participants.
Mutation analysis

DNA was extracted by standard phenol-chloroform procedures. All coding exons and flanking intron sequences of BRCA1 and BRCA2 were analysed by denaturing high performance liquid chromatography (dHPLC) or direct sequencing. dHPLC was carried out on an automated instrument (Transgenomic Inc., San Jose, CA); optimal temperatures for heteroduplex detection were determined using WAVEMAKER software (Transgenomic). BRCA1 exons 9, 11, 13, 16 and BRCA2 exon 22 were directly investigated by sequencing because of their high content of polymorphic variants. DNA sequencing was carried out on an ABI 310 DNA analyser (Applied Biosystems) using the ABI PRISM BigDye terminators cycle sequencing kit (Applied Biosystems).

Mutation nomenclature follows the Human Genome Variation Society (URL: http://www.hgvs.org/mutnomen/) recommendations. The DNA mutation numbering is based on the BRCA1 and BRCA2 cDNA sequences (reference sequences: NM_007296.2 and NM_000059.3, respectively) with the A of the ATG translation-initiation codon numbered as +1 . Amino acid numbering starts with the translation initiator methionine as +1 .

Microsatellite analysis

Thirty-eight individuals belonging to 14 families segregating two recurrent BRCA1 mutations, c.3228_3229delAG $(n=11)$ and c.3285delA $(n=3)$ and 54 controls, were genotyped at nine short tandem repeat markers located within or adjacent to $B R C A 1$. The following microsatellites, listed in order from centromere to telomere, were analyzed: D17S1872, D17S250, D17S800, D17S1328, D17S1323, D17S1325, D17S902, D17S806 and D17S588 (Fig. 1). PCR primer sequences were obtained from the Genome Database (URL: http://www.gdb.org). Forward primers were labelled with 6-FAM or TET fluorescent dyes and PCR products were analysed on a model 310 automated sequencer (Applied Biosystems). Product size determination was assessed with Genotyper (version 2.1) software (Applied Biosystems).

Haplotyping and estimate of mutation age

Haplotypes were constructed manually, assuming the least number of possible recombinations. Mutation age estimate was carried out with the DMLE+2.2 software program (URL: http://www.dmle.org) [9].

The method implemented in the DMLE+2.2 software is an extension of the Bayesian LD mapping method of Rannala and Reeve [10] that was initially designed for high-resolution mapping of a disease mutation based on the 
(a)

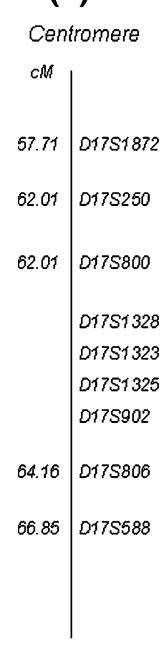

Telomere (b)

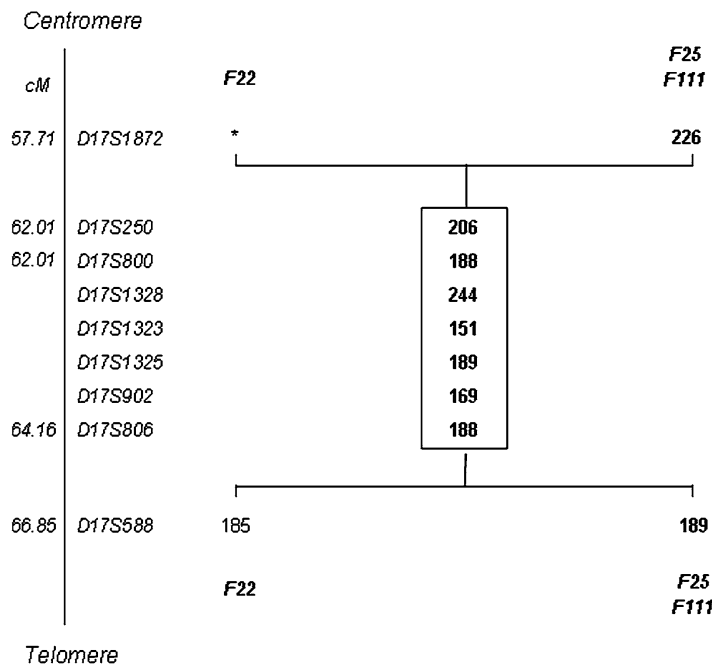

Fig. 1 Haplotype branching trees derived from haplotype analysis. The most common haplotype is indicated in bold numbers. The markers used are shown together with their position in the Marshfield genetic map. Family haplotypes are indicated with the corresponding family number (in bold and italics). a Haplotypes of families segregating BRCA1 c.3228_3229delAG. b Haplotypes of families segregating $B R C A 1$ c.3285delA observed linkage disequilibrium between the mutation and linked markers in DNA samples of disease chromosomes. It uses the Markov chain Monte Carlo methods to generate the marginal posterior probability density of mutation age, based on the following parameters: observed haplotypes or genotypes in normal and affected chromosomes, map distances between markers and mutation site, fraction of mutated chromosomes sampled, and estimated population growth rate.

We used haplotypes for the nine 17q21 microsatellite markers in affected and unaffected chromosomes, with the following parameters: (a) chromosome map distances derived from the Marshfield and/or Genéthon sex-average genetic maps (URL: http://www.ncbi.nlm.nih.gov/map view/) and by Bergman et al. [11]; (b) population growth rate: 0.054 ; (c) proportion of mutation-carrying chromosomes sampled: 0.00698 .

The population growth rate $(r)$ was estimated from the equation: $N=N_{0} \mathrm{e}^{g r}$, in which $N$ is the estimated present population size, $N_{0}$ is the estimated size of the population at reference time and $g$ is the number of generations between these two time points. The population of the city of Florence currently comprises about 330,000 people. Historical and demographic data indicate that it included about 15,000 people in year 1200 [12] and 59,500 in year 1550; accordingly, the average growth rate of this population was estimated to be 0.085 between years 1200 and present time and 0.119 from 1550 to the present time, assuming 25 years/generation. There are no data regarding the population of the entire region of Tuscany before year
1550; in that year it was estimated to include about 912,000 individuals [12] and now comprises about 3,619,000 inhabitants; the approximate growth rate per generation is therefore 0.076 . We then calculated the ratio between the growth rates of the city of Florence (0.119) and of the entire region, inclusive of rural areas (0.076), for the period 1550 to present. The value thus obtained, 1.57, was used to estimate the growth rate since 1200 of the whole region, based on the urban data only $(0.085)$ for this period. We thus calculated a value of $r=0.054=(0.085 \times 1 / 1.57)$, which was subsequently used for mutation age estimates.

The proportion of mutation-carrying chromosomes sampled was estimated from a population of $1,175,000$ inhabitants in Florence and the surrounding provinces of Prato and Arezzo in Central-Eastern Tuscany assuming a prevalence of BRCA1 mutation carriers of 0.014 (1:714). The latter represents the median value calculated from a meta-analysis of prevalence data available for populations of European ancestry [13-17], since estimates of BRCAI mutation prevalence are not available for the Italian population.

\section{Results}

Mutation analysis and phenotypic characteristics

Germline deleterious $B R C A 1$ and $B R C A 2$ mutations were identified in 22 and 13 out of 104 probands from CentralEastern Tuscany, respectively. We found ten different 
Table 1 BRCA1 and BRCA2 deleterious mutations in high risk families from Tuscany

\begin{tabular}{|c|c|c|c|c|c|}
\hline Gene & Description of mutation & Effect of mutation & $\begin{array}{l}\text { Number of families } \\
\text { with the same mutation }\end{array}$ & BIC nomenclature $^{\mathrm{a}}$ & $\begin{array}{l}\text { Number of times } \\
\text { recorded in BIC }\end{array}$ \\
\hline \multirow[t]{10}{*}{$B R C A 1$} & c.3228_3229delAG & p.Arg1076fs & 9 & 3347_3348delAG & 24 \\
\hline & c.3285delA & p.Lys1095fs & 3 & 3404delA & 0 \\
\hline & c.1377_1378insA & p.Ile460fs & 2 & 1499insA & 12 \\
\hline & c.5062_5064delTGT & p.Val1688del ${ }^{\text {b }}$ & 2 & 5181_5183delTGT & 6 \\
\hline & c.182_183delTG & p.Cys61fs & 1 & 301_302delGT & 0 \\
\hline & c.2155_2168del14 & p.Lys719fs & 1 & 2274_2287del14 & 0 \\
\hline & c.2296_2297delAG & p.Ser766fs & 1 & 2415_2416delAG & 3 \\
\hline & c.2405_2406delTG & p.Val802fs & 1 & 2524_2525delTG & 5 \\
\hline & c. $4327 \mathrm{C}>\mathrm{T}$ & p.Arg1443Stop & 1 & $4446 \mathrm{C}>\mathrm{T}$ & 126 \\
\hline & c. $5251 \mathrm{C}>\mathrm{T}$ & p.Arg1751Stop & 1 & $5370 \mathrm{C}>\mathrm{T}$ & 29 \\
\hline \multirow[t]{12}{*}{$B R C A 2$} & c. $9117 \mathrm{G}>\mathrm{A}$ & r.8954_9117del (Exon 23 skipping) ${ }^{\mathrm{c}}$ & 2 & $9345 \mathrm{G}>\mathrm{A}$ & 14 \\
\hline & c. $289 \mathrm{G}>\mathrm{T}$ & p.Glu97Stop & 1 & $517 \mathrm{G}>\mathrm{T}$ & 0 \\
\hline & c. $632-2 A>G$ & r.517_631del (Exon 7 skipping) & 1 & IVS7-2A $>$ G & 0 \\
\hline & c. $2950 \mathrm{G}>\mathrm{T}$ & p.Glu984Stop & 1 & $3178 \mathrm{G}>\mathrm{T}$ & 0 \\
\hline & c.3860delA & p.Asn1287fs & 1 & 4088delA & 2 \\
\hline & c.5086_5087insA & p.Gly1696fs & 1 & 5314insA & 0 \\
\hline & c.5851_5854delAGTT & p.Ser1951fs & 1 & 6079_6082delAGTT & 11 \\
\hline & 6468_6469delTC & p.Ser2156fs & 1 & 6696_6697delTC & 22 \\
\hline & c.7707delT & p.Gly2569fs & 1 & 7935delT & 0 \\
\hline & c. $7963 \mathrm{C}>\mathrm{T}$ & p.Gln2655Stop & 1 & $8191 \mathrm{C}>\mathrm{T}$ & 0 \\
\hline & c. $8878 \mathrm{C}>\mathrm{T}$ & p.Gln2960Stop & 1 & $9106 \mathrm{C}>\mathrm{T}$ & 10 \\
\hline & c. $9501+3 \mathrm{~A}>\mathrm{T}$ & r.9257_9501del (Exon 25 skipping) ${ }^{\mathrm{d}}$ & 1 & $\operatorname{IVS} 25+3 \mathrm{~A}>\mathrm{T}$ & 15 \\
\hline
\end{tabular}

a BIC: Breast Cancer Information Core; note that sequence variants are designated differently in this study (for which the nomenclature recommendations of the Human Genome Variation Society were used) and in BIC (http://research.nhgri.nih.gov/bic/)

b This variant is considered to be deleterious based on functional studies [4]

c This variant is considered to be deleterious based on RNA studies [18]

d This variant is considered to be deleterious based on RNA studies (this study; data not shown)

$B R C A 1$ and twelve different $B R C A 2$ germline mutations (Table 1). Four of the ten BRCA1 mutations and one of the twelve $B R C A 2$ mutations were observed in more than one family. The BRCAl c.3228_3229delAG and c.3285delA mutations were observed in nine and three families, respectively. Two additional BRCA1 mutations, c.1377_1378insA and c.5062 5064delTGT and one $B R C A 2$ variant, c. $9117 \mathrm{G}>\mathrm{A}$, were observed in two families each.

\section{Haplotype analysis}

Three families with the c.3285delA mutation and 11 families carrying the c.3228_3229delAG, as well as 18 nuclear families used as controls, were investigated.

Haplotype analysis using polymorphic markers spanning the BRCAl locus was performed on probands and, when possible, on additional family members. Two to seven family members were genotyped in 8 of the 11 families segregating the c.3228_3229delAG and in 1 of the 3 families with the c.3285delA. In the remaining families only the index case was available for genotyping.

Two distinct haplotypes were associated with each of the two recurrent BRCA1 mutations, c.3228_3229delAG and c.3285delA (Fig. 1). These haplotypes were absent in non-carriers from the families segregating the two mutations and were not found in control chromosomes. In addition, in all families with only one individual available for analysis, the observed genotypes were compatible with the shared haplotypes identified in families with the same mutation.

Age estimate of the BRCA1 c.3228_3229delAG mutation

The DMLE +2 program was used to estimate the age of the c.3228_3229delAG mutation based on haplotype data from patients and controls. Using the median prevalence of 1:714 to estimate the number of mutation-carrying chromosomes sampled and considering a growth rate of 0.054 , 


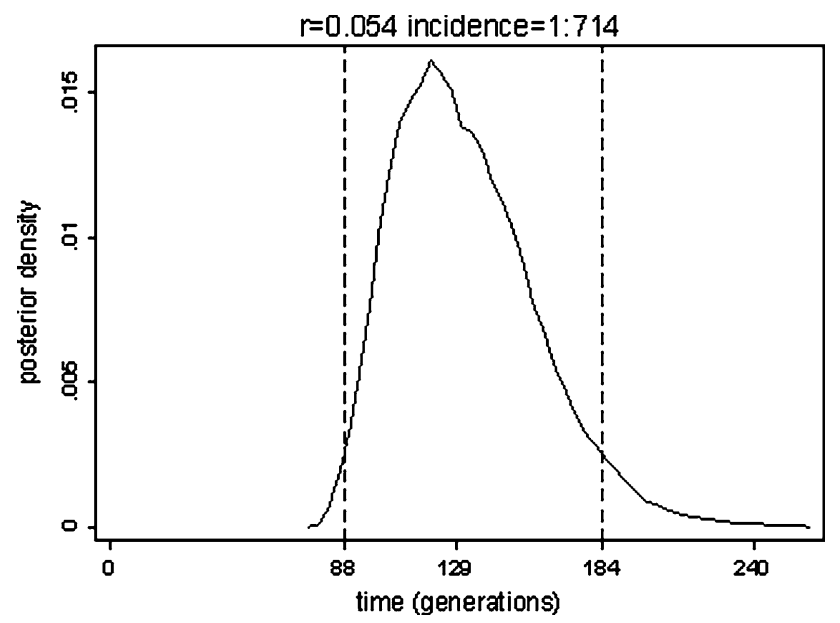

Fig. 2 Plot of the posterior probability densities of mutation age expressed in number of generations estimated with DMLE software. Broken lines define the boundaries of the $95 \%$ confidence interval

the mutation age was estimated to be $\sim 129$ generations (95\% credible set: $88-184)$ (Fig. 2).

Clinical characteristics associated with the BRCAI c.3228_3229delAG mutation

Ovarian cancer was recorded in 8 of the 11 families exhibiting the BRCAl c.3228_3229delAG mutation (Table 2). The age at first BC diagnosis ranged between 30 and 82 years (median 43.5 years). The age at first OC diagnosis ranged between 30 and 68 years (median
47.0 years). Interestingly, male $\mathrm{BC}$ cases were present in 3/11 families with the BRCA1 c.3228_3229delAG mutation.

\section{Discussion}

In the present study, we have investigated high risk breastovarian cancer families referred to a single breast cancer family clinic of Central Italy in the period 1999-2005. The majority of the families investigated $(104 / 185 ; 56.2 \%)$ originate from Florence and the surrounding provinces of Prato, Arezzo and Pistoia (Fig. 3). Of the 104 probands of Tuscan origin, $35(35.65 \%)$ were heterozygotes for a $B R C A 1 / B R C A 2$ deleterious mutation. Although the BRCA1/BRCA2 mutation spectrum was highly variable, two mutations, c.3228_3229delAG and c.3285delA, were present in $57 \%$ of all BRCAl-attributable families. The BRCA1 c.3285delA has never been reported in the Breast Cancer Information Core (BIC) (URL: http://research. nhgri.nih.gov/bic/) and, to the best of our knowledge, in Italy. Two additional BRCA1 mutations, c.1377_1378insA and c.5062_5064delTGT, were detected in two unrelated families each in our series. Both of these have been shown to be Italian founder mutations, originating from Western Tuscany [3] and North-Eastern Italy [4], respectively. Therefore, overall recurrent founder mutations accounted for $72.7 \%$ of $B R C A 1$ mutations in our series.

The $B R C A 2$ mutation spectrum was more variable. We found two unrelated families carrying the same $B R C A 2$ c. $9345 \mathrm{G}>\mathrm{A}$ mutation causing exon 23 skipping, already described in another patient from Pisa, Tuscany [18]. In

Table 2 Families with the BRCA1 c.3228_3229delAG mutation

\begin{tabular}{lllll}
\hline Family ID & Sex of proband & $\begin{array}{l}\text { Phenotype and } \\
\text { age at diagnosis }^{\mathrm{b}}\end{array}$ & $\begin{array}{l}\text { Family history of breast and } \\
\text { ovarian cancers and age of diagnosis }^{\mathrm{c}}\end{array}$ & $\begin{array}{l}\text { Family history } \\
\text { of other cancers }^{\mathrm{d}}\end{array}$ \\
\hline F11 & Female & BC42+44 & M-BC39, MA-BC? & Colon \\
F41 & Female & BC34 & S-OC41, M-OC56, MA-OC68, MGM-OC43 & Gastric, leukaemia \\
F61 & Female & BC57 & M-BC82, MA-BC45, MA-BC60 & Colon, brain, pancreas \\
F74 & Female & OC52, BC54 & M-OC56 & Cerebellar \\
F114 & Female & OC42 & MA-OC66 & Gyn? \\
F187 & Female & BC43 & S-OC44, F-BC40, PGM-BC71, PGGM-BC42 & Gastric, colon, lung \\
F188 & Female & BC42 & S-BC47, S-BC52, S-OC45, N-BC37, N-BC37 & None \\
F223 & Female & OC44 & S-BC41, M-BC30, MA-OC50, MGM-OC49 & None \\
F263 & Female & OC53 & M-OC43 & Gyn? \\
F5 & Male & BC60 & S-BC45, S-BC41+OC41, PA-OC30, PC-OC57, PC-BC64 & Leukaemia \\
F56 & Male & BC55 & MC-BC31, PA-BC70 & Colon, prostate, stomach, liver
\end{tabular}

${ }^{a}$ Families ascertained in a population-based study of male breast cancer (Ottini personal communication)

b BC: breast cancer; OC: ovarian cancer

${ }^{\mathrm{c}}$ M: mother; F: father; S: sister; N: niece; PGM: paternal grandmother; PGGM: paternal grand-grandmother; MA: maternal aunt; MC: maternal cousin; MGM: maternal grandmother; PA: paternal aunt; PC: paternal cousin

d Gyn?: undefined gynaecological cancer 
Fig. 3 Geographic distribution (province of residence) of the families segregating founder BRCA1 mutations in Tuscany. Each family is represented by the symbol corresponding to the observed mutation

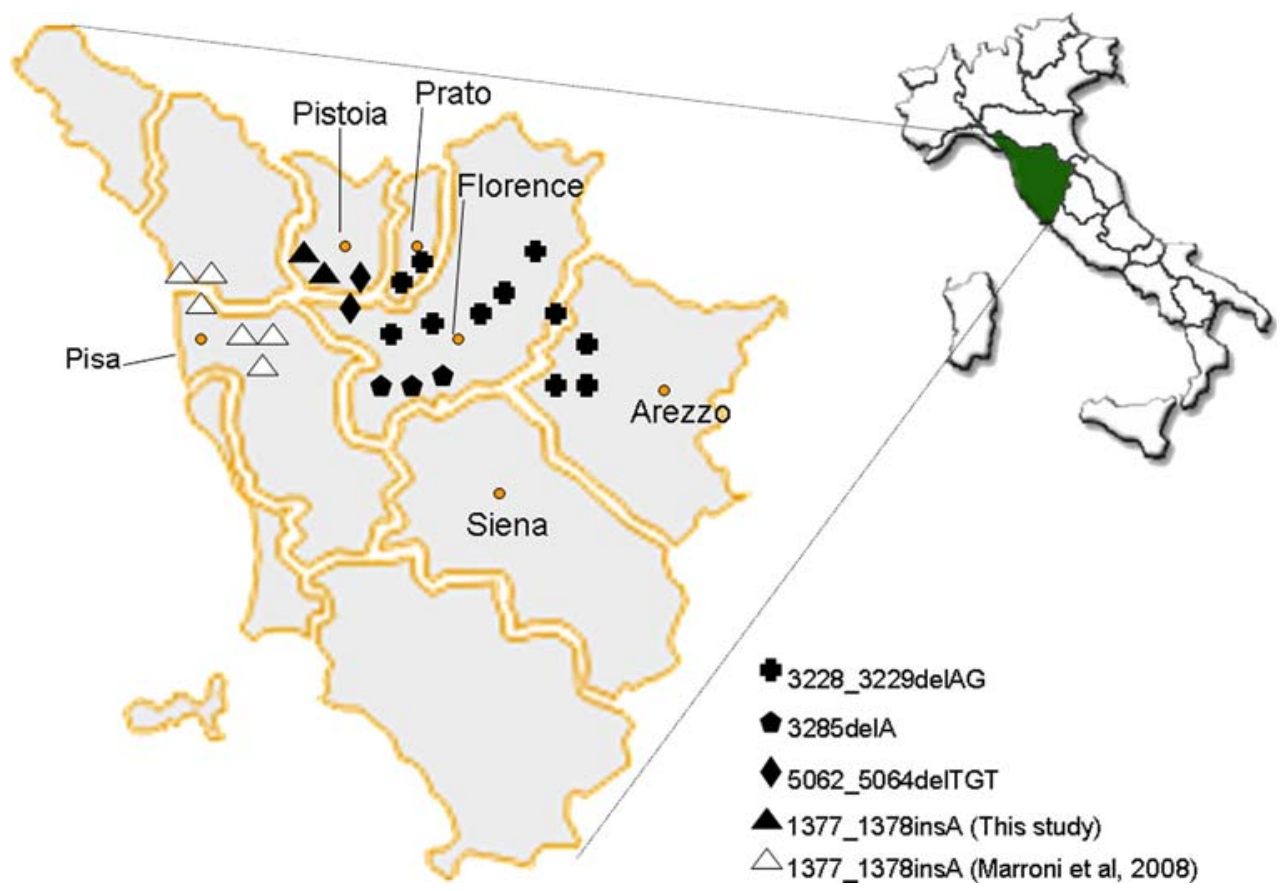

addition, the BRCA2 c.6468_6469delTC frameshift mutation, identified in a single family in this study, has previously been described in an unrelated male breast cancer patient from Florence [19].

The most frequent $B R C A 1$ germline mutations identified in our sample are c.3228_3229delAG and c.3285delA. Haplotype analysis of nine microsatellite markers, covering a region of $\sim 9.14 \mathrm{Mb}$ surrounding BRCA1 on $17 \mathrm{q} 21$, was conducted on 14 families and the results obtained clearly indicate that both mutations can be traced back to common ancestors.

We then used DMLE+2.2 software to estimate the age of the BRCA1 c.3228_3229delAG; the c.3285delA mutation was not investigated because the number of families in which it was identified was considered inadequate to estimate its age.

The estimate of the number of generations since the origin of the BRCA1 c.3228_3229delAG mutation was 129 (95\% credible set: $88-184)$ generations, corresponding to $\sim 3,225$ years (95\% confidence intervals: 2200-4600). Therefore its origin in Tuscany should date back to the Villanovian and Etruscan periods, indicating that it is one of the oldest founder mutations so far described in breastovarian cancer predisposing genes (Table 3). However, it is worth nothing that the DMLE+2.2 method estimates the time of origin of the mutation, which may be older than that of the most recent common ancestor estimated by the other methods used in the studies reported in Table 3 [10, 20]. In addition, DMLE+2.2 estimates are very sensitive to the population growth rate; i.e. using a growth rate of 0.085 , calculated only on the Florentine population, the estimated number of generations since the origin of the mutation was 92 (95\% credible set: 65-127).

Interestingly, male breast cancer was present in three out of the eleven families segregating the BRCA1 c.3228_ 3229delAG mutation. It is well known that male breast carcinoma is associated with deleterious germline mutations in BRCA2, and the estimated cumulative risk of breast carcinoma by age 70 years is $6.3 \%$ [21] to $6.8 \%$ [22] among BRCA2 mutation male heterozygotes. However, the relationship between male breast carcinoma and deleterious germline mutations in BRCAl is not as well established. BRCAl mutations have been detected at very low frequency in series of unselected male breast cancer patients [19, 23-25]. On the other hand, a lifetime risk of male breast cancer of $5.8 \%$ in BRCA1 mutation carriers has been calculated, but this estimate was based on data from high-risk families and was not adjusted for ascertainment [26]. More recently, the cumulative risk of breast cancer by age 70 years in BRCA1 male carriers was estimated at $1.2 \%$ in a very large US cohort of BRCA1/BRCA2 families [22]. The high number of BRCAl c.3228_3229delAG families with male breast cancer cases might be a specific phenotypic effect of the mutation itself; however, there are 24 previous reports of BRCA1 c.3228_3229delAG in BIC and, to our knowledge, no association with male breast cancer has been pointed out. Therefore, it is possible that the genetic background of Tuscan male carriers influences phenotypic expression of this $B R C A 1$ variant. The presence of mutations in other breast cancer predisposing genes or in modifier genes might increase the risk of breast cancer among male heterozygotes for this specific mutation. 
Table 3 Age estimates for $B R C A 1$ and BRCA2 founder mutations

\begin{tabular}{lllll}
\hline Gene & $\begin{array}{l}\text { Mutation according } \\
\text { to BIC nomenclature } \\
\text { (number of families) }\end{array}$ & $\begin{array}{l}\text { Mutation age } \\
\text { in generations } \\
\text { (confidence interval) }\end{array}$ & $\begin{array}{l}\text { Country or } \\
\text { population }\end{array}$ & Reference \\
\hline BRCA1 & 3347_3348delAG (11) & $129(88-183)$ & Tuscany, Italy & Present study \\
& 1499insA (14) & $30(22-56)$ & Tuscany, Italy & {$[3]$} \\
& G1738R & $11(4-24)$ & Greece & {$[27]$} \\
& 3171ins5 (18) & 50 & South Sweden & {$[11]$} \\
& 3744delT (8) & $23-36$ & Finland & {$[28]$} \\
& 4216-2A $>$ G (9) & $<10$ & Finland & {$[28]$} \\
& 2804delAA (19) & $32(15-49)$ & Netherlands & {$[29]$} \\
& 185delAG (17) & $46(23-80)$ & Ashkenazi Jews & {$[30]$} \\
& 4184del4 (6) & $170(70-350)$ & European, mixed & {$[30]$} \\
5382insC (19) & $38(18-68)$ & & {$[30]$} \\
& Intron 5 splice (5) & $75(19-165)$ & Portugal & {$[30]$} \\
& 1294del40 (6) & $9(1-45)$ & Finland & {$[31]$} \\
156-157insAlu (14) & $120-130$ & Finland & {$[28]$} \\
& 9346-2A $>$ G (9) & $7-11$ & Finland & {$[28]$} \\
\hline
\end{tabular}

The observation that a high proportion of families with $B R C A 1$ alterations from central-eastern Tuscany harbours a limited number of founder mutations has significant impact on clinical management of at risk subjects. Direct screening for these mutations could be undertaken as a first step for molecular analysis, at least in individuals of ascertained Tuscan ancestry. The identification of a large set of families carrying an identical mutation that predisposes to breast and ovarian cancer will provide unique opportunities to study the effect of other genetic and environmental factors on penetrance and disease phenotype. Should an increased risk of male breast cancer associated with the c.3228_3229delAG sequence variant be confirmed, it would be appropriate to consider offering appropriate surveillance to male carriers of this mutation.

Acknowledgements The study was supported by Regione Toscana in the frame of the High-Risk Cancer Family Project and from a grant of Ente Cassa di Risparmio, Firenze, Italy.

\section{References}

1. Ferla R, Calò V, Cascio S et al (2007) Founder mutations in BRCA1 and BRCA2 genes. Ann Oncol 18(Suppl 6):vi93-vi98. doi:10.1093/annonc/mdm234

2. Baudi F, Quaresima B, Grandinetti C et al (2001) Evidence of a founder mutation of BRCA1 in a highly homogeneous population from Southern Italy with breast/ovarian cancer. Hum Mutat 18:163-164. doi:10.1002/humu.1167

3. Marroni F, Cipollini G, Peissel B et al (2008) Reconstructing the genealogy of a BRCA1 founder mutation by phylogenetic analysis. Ann Hum Genet 72:310-318. doi:10.1111/j.1469-1809. 2007.00420.x
4. Malacrida S, Agata S, Callegaro $\mathrm{M}$ et al (2008) BRCAl p.Val1688del is a deleterious mutation that recurs in breast and ovarian cancer families from Northeast Italy. J Clin Oncol 26:2631. doi:10.1200/JCO.2007.13.2118

5. Pisano M, Cossu A, Persico I et al (2000) Identification of a founder BRCA2 mutation in Sardinia. Br J Cancer 82:553-559. doi:10.1054/bjoc. 1999.0963

6. Monne M, Piras G, Fancello P et al (2007) Identification of a founder $B R C A 2$ mutation in Sardinian breast cancer families. Fam Cancer 6:73-79. doi:10.1007/s10689-006-9107-7

7. Berry DA, Iversen ES Jr, Gudbjartsson DF et al (2002) BRCAPRO validation, sensitivity of genetic testing of BRCA1/ $B R C A 2$, and prevalence of other breast cancer susceptibility genes. J Clin Oncol 20:2701-2712. doi:10.1200/JCO.2002. 05.121

8. Ottini L, Rizzolo P, Zanna I et al (2008) BRCA1/BRCA2 mutation status and clinical-pathologic features of 108 male breast cancer cases from Tuscany: a population-based study in Central Italy. Breast Cancer Res Treat. doi:10.1007/s10549-008-0194-Z

9. Reeve JP, Rannala B (2002) DMLE+: Bayesian linkage disequilibrium gene mapping. Bioinformatics 18:894-895. doi: 10.1093/bioinformatics/18.6.894

10. Rannala B, Reeve JP (2001) High-resolution multipoint linkagedisequilibrium mapping in the context of a human genome sequence. Am J Hum Genet 69:159-178. doi:10.1086/321279

11. Bergman A, Einbeigi Z, Olofsson U et al (2001) The western Swedish BRCA1 founder mutation 3171 ins 5 ; a $3.7 \mathrm{cM}$ conserved haplotype of today is a reminiscence of a 1500-year-old mutation. Eur J Hum Genet 9:787-793. doi:10.1038/sj.ejhg.5200704

12. Beloch KJ (1995) Storia della popolazione d'Italia. In: Del Panta L, Sonnino E (eds) Le Lettere, Firenze, pp xxxii, 695

13. Ford D, Easton DF, Peto J (1995) Estimates of the gene frequency of BRCA1 and its contribution to breast and ovarian cancer incidence. Am J Hum Genet 57:1457-1462

14. Whittemore AS, Gong G, Itnyre J (1997) Prevalence and contribution of BRCA1 mutations in breast cancer and ovarian cancer: results from three US population-based case-control studies of ovarian cancer. Am J Hum Genet 60:496-504 
15. Risch HA, McLaughlin JR, Cole DE et al (2006) Population $B R C A 1$ and $B R C A 2$ mutation frequencies and cancer penetrances: a kin-cohort study in Ontario, Canada. J Natl Cancer Inst 98:1694-1706

16. Whittemore AS, Gong G, John EM et al (2004) Prevalence of BRCA1 mutation carriers among US non-Hispanic whites. Cancer Epidemiol Biomarkers Prev 13:2078-2083

17. Antoniou AC, Pharoah PD, McMullan G et al (2002) A comprehensive model for familial breast cancer incorporating BRCA1, BRCA2 and other genes. Br J Cancer 86:76-83. doi: 10.1038/sj.bjc.6600008

18. Bonatti F, Pepe C, Tancredi M et al (2006) RNA-based analysis of BRCA1 and BRCA2 gene alterations. Cancer Genet Cytogenet 170:93-101. doi:10.1016/j.cancergencyto.2006.05.005

19. Ottini L, Masala G, D'Amico C et al (2003) BRCA1 and BRCA2 mutation status and tumor characteristics in male breast cancer: a population-based study in Italy. Cancer Res 63:342-347

20. Slatkin M, Rannala B (2000) Estimating allele age. Annu Rev Genomics Hum Genet 1:225-249. doi:10.1146/annurev.genom. 1.1.225

21. Easton DF, Steele L, Fields P et al (1997) Cancer risks in two large breast cancer families linked to $B R C A 2$ on chromosome 13q12-13. Am J Hum Genet 61:120-128. doi:10.1086/513891

22. Tai YC, Domchek S, Parmigiani G et al (2007) Breast cancer risk among male BRCA1 and BRCA2 mutation carriers. J Natl Cancer Inst 99:1811-1814. doi:10.1093/jnci/djm203

23. Friedman LS, Gayther SA, Kurosaki T et al (1997) Mutation analysis of BRCA1 and BRCA2 in a male breast cancer population. Am J Hum Genet 60:313-319

24. Csokay B, Udvarhelyi N, Sulyok Z et al (1997) High frequency of germ-line BRCA2 mutations among Hungarian male breast cancer patients without family history. Cancer Res 59:995-998
25. Evans DG, Bulman M, Young K et al (2008) BRCA1/2 mutation analysis in male breast cancer families from North West England. Fam Cancer 7:113-117. doi:10.1007/s10689-007-9153-9

26. Brose MS, Rebbeck TR, Calzone KA et al (2002) Cancer risk estimates for BRCA1 mutation carriers identified in a risk evaluation program. J Natl Cancer Inst 94:1365-1372

27. Anagnostopoulos T, Pertesi M, Konstantopoulou I et al (2008) G1738R is a BRCA1 founder mutation in Greek breast/ovarian cancer patients: evaluation of its pathogenicity and inferences on its genealogical history. Breast Cancer Res Treat 110:377-385. doi:10.1007/s10549-007-9729-y

28. Sarantaus L, Huusko P, Eerola H et al (2000) Multiple founder effects and geographical clustering of BRCA1 and BRCA2 families in Finland. Eur J Hum Genet 8:757-763. doi:10.1038/ sj.ejhg. 5200529

29. Peelen T, van Vliet M, Petrij-Bosch A et al (1997) A high proportion of novel mutations in BRCAl with strong founder effects among Dutch and Belgian hereditary breast and ovarian cancer families. Am J Hum Genet 60:1041-1049

30. Neuhausen SL, Mazoyer S, Friedman L et al (1996) Haplotype and phenotype analysis of six recurrent BRCA1 mutations in 61 families: results of an international study. Am J Hum Genet 58:271-280

31. Machado PM, Brandão RD, Cavaco BM et al (2007) Screening for a $B R C A 2$ rearrangement in high-risk breast/ovarian cancer families: evidence for a founder effect and analysis of the associated phenotypes. J Clin Oncol 25:2027-2034. doi:10.1200/JCO. 2006.06.9443 